\title{
Age- and gender-related differences in drug utilisation and adverse drug reaction patterns among patients in a coronary care unit
}

\author{
Nitin Subhashchandra Kunnoor ${ }^{1}$, MBBS, MD, Padmini Devi ${ }^{1}$, MBBs, MD, Deepak Yogesh Kamath ${ }^{2}$, MBBS, MD
} Naveen Anthony ${ }^{1}$, MBBS, MD, Jesso $\underline{\text { George }}^{1}$, MBBS, MD

INTRODUCTION This study aimed to examine age- and gender-related differences in the comorbidities, drug utilisation and adverse drug reaction (ADR) patterns of patients admitted to a coronary care unit (CCU).

METHODS The present study was a retrospective cohort study. Two trained physicians independently reviewed the case records of CCU patients over a period of one year (Jan-Dec 2008). The demographic, clinical, and drug prescription data of the patients were analysed according to age group (18-59 years vs $\geq 60$ years) and gender.

RESULTS A total of 574 patients were admitted to the CCU during the study period. Of these 574 patients, $65.2 \%$ were male, and $48.4 \%$ were $\geq 60$ years old. No significant gender-based differences were found for the prescription of cardiovascular and non-cardiovascular drugs, and ADR patterns $(p>0.05)$. Male patients aged $\geq 60$ years were found to have a higher rate of polypharmacy than those aged $18-59$ years $(p=0.001)$. The duration of hospital stay was longer in male than female patients $(p=0.008)$, and the duration of CCU stay was longer for male patients aged $\geq 60$ years than males aged $18-59$ years $(p=0.013)$. Compared to patients aged $18-59$ years, a greater number of patients aged $\geq 60$ years were prescribed cardiovascular $(p=0.006)$ and non-cardiovascular drugs $(p=0.015)$. Patients aged $\geq 60$ years also had a higher rate of polypharmacy $(p=0.001)$ and ADRs $(p=0.013)$, and a longer duration of CCU stay $(p=0.013)$. Renal $(p=0.047)$ and cutaneous $(p=0.003)$ ADRs were found to be more common in patients aged $\geq 60$ years.

CONCLUSION No major gender-related differences were observed in the prescription, drug utilisation and ADR patterns of our study cohort. Higher drug utilisation, ADR rates, and longer duration of CCU stay were noted in patients aged $\geq 60$ years.

Keywords: adverse drug reactions, age, coronary care unit, drug utilisation, gender

\section{INTRODUCTION}

Cardiovascular diseases (CVDs) have emerged as the leading cause of deaths worldwide. Low- and middle-income countries account for more than $80 \%$ of the global burden of CVDs. By 2020, deaths from CVDs are predicted to rise to four million per year in China and almost five million per year in India. ${ }^{(1)}$

Women tend to be diagnosed at an older age and have more comorbidities, such as diabetes mellitus (DM) and obesity. ${ }^{(2)}$ Although men are more likely to have episodes of myocardial infarction (MI), women who do suffer an episode of $\mathrm{MI}$ are more likely to have a second $\mathrm{MI}$, develop heart failure, or suffer subsequent sudden cardiac death. ${ }^{(3)}$ Increasing age, lipid abnormalities, high blood pressure, obesity, DM and smoking are major risk factors for CVDs in both genders. ${ }^{(4)}$ Data from the INTERHEART study indicates that the lower prevalence of acute coronary syndrome (ACS) among women of younger ages (i.e. < 60 years) is largely explained by a lower risk factor burden. ${ }^{(5)}$ Recent data from the National Health and Nutrition Examination Survey has shown that, over the past two decades, the prevalence of MI has increased in women aged 35-54 years, while declining in men of the same age group. ${ }^{(6)}$
Age and gender inequalities exist in the preventive pharmacotherapy of CVDs, particularly in cholesterol-lowering treatment. ${ }^{(7,8)}$ Previous research has shown a 'treatment-risk' paradox for secondary prevention, whereby patients become less likely to receive appropriate treatment as they advance in age. ${ }^{(9,10)}$ Compared to men, women have been found to be less frequently prescribed both antihypertensive and lipid-lowering drugs. $^{(8,11)}$

Up to $5 \%$ of all hospital admissions are the result of adverse drug reactions (ADRs). It has been reported that patients with adverse drug events spend an average of 2.2 days longer in hospitals. ${ }^{(12)}$ Among the known risk factors for ADRs (e.g. advanced age, polypharmacy, liver and renal disease), female gender has been shown to have a 1.5- to 1.7-fold increased risk of developing an ADR as compared to the male gender. ${ }^{(13,14)}$ The reasons for the age- and gender-related differences observed in ADRs include pharmacokinetic, pharmacodynamic, immunological and hormonal factors, as well as differences in the use of medications in female and elderly ( $\geq 60$ years) patients.

Therapies in critical care settings are challenging due to the coexistence of multiple comorbidities that warrant

${ }^{1}$ Department of Pharmacology, St John's Medical College, ${ }^{2}$ St John's Research Institute, Bangalore, Karnataka, India

Correspondence: Dr Nitin S Kunnoor, Tutor, Department of Pharmacology, St John's Medical College, Bangalore 560034, Karnataka, India. drnitinskunnoor@yahoo.in 
polypharmacy. The interplay of multiple comorbidities and polypharmacy in intensive care settings is a possible risk factor for ADRs, resulting in higher ADR rates than that in out- and inpatient settings. ${ }^{(15)}$ A study by Mohebbi et al documented the rate of ADRs attributed to cardiovascular drugs alone in the coronary care unit (CCU) to be as high as $24 \% .{ }^{(16)}$ The authors also found that $22 \%$ of ADRs in the CCU were severe ADRs, and that $7 \%$ of ADRs were potentially preventable. ${ }^{(16)}$

In India, there is a paucity of data regarding the age- and gender-related aspects of drug utilisation and ADR patterns in critical care settings. Thus, the objective of the present study was to determine the age- and gender-related differences in the drug utilisation and ADR patterns of patients admitted to the CCU of a tertiary care hospital.

\section{METHODS}

The present study was a retrospective cohort study conducted in the CCU of St John's Medical College Hospital, Bangalore, India. The hospital is a 1,200-bedded multispecialty, charitable hospital. The study method employed and the preliminary results on the patterns, predictors and preventability of ADRs that occurred in the CCU of the hospital were reported in our earlier paper. ${ }^{(17)}$ Study approval was obtained from the Institutional Ethical Review Board of St John's Medical College.

The case records of consecutive patients admitted to the CCU from 1 January to 31 December 2008 (i.e. a period of one year) were retrospectively reviewed. Two physicians independently reviewed and extracted relevant data from the case records. Data extracted included the patient's demographic data, existence of comorbid conditions, diagnosis at admission, investigations performed, treatments prescribed, duration of stay in the CCU and hospital, and information on observed ADRs (i.e. organ system involved, suspected drug, reaction time, management and outcome). Data was collected using standardised case record forms. For the purpose of standardisation, we used the established international terminologies of the Anatomical Therapeutic Classification (ATC) for medication, ${ }^{(18)}$ the International Classification of Diseases version 10 for diagnoses ${ }^{(19)}$ and the World Health Organization's definition for adverse drug reaction. ${ }^{(20)}$ The differences observed in the prescription of cardiovascular and non-cardiovascular drugs were analysed. Drugs were classified into different pharmacological groups and subgroups, according to the third and fourth levels of the ATC. Further detailed analysis of the drug data focused on the cardiovascular drugs prescribed based on the ATC classification codes ' $\mathrm{B}$ ' and ' $\mathrm{C}$ '.

Data was analysed according to age (18-59 years vs $\geq 60$ years) and gender (male vs female), and stratified according to age in gender (male [18-59 years vs $\geq 60$ years] and female [18-59 years $v s \geq 60$ years]). Polypharmacy (i.e. $\geq 10$ drugs per prescription), duration of $\mathrm{CCU}$ stay, and duration of hospital stay were analysed based on age and gender.
Renal dysfunction was defined based on the estimated creatinine clearance values that were calculated using the Cockroft-Gault equation - values of $120 \mathrm{~mL} / \mathrm{min} / 1.73 \mathrm{~m}^{2}$ and $100 \mathrm{~mL} / \mathrm{min} / 1.73 \mathrm{~m}^{2}$ were considered normal for men and women, respectively. Descriptive data was presented as mean \pm standard deviation (SD), median and interquartile range (IQR), and frequencies. Chi-square test and Mann-Whitney $U$ test were appropriately used to compare characteristics between the two genders (male vs female), and between the two age groups ( $18-59$ years vs $\geq 60$ years). The Statistical Package for the Social Sciences version 16.0 software (SPSS Inc, Chicago, IL, USA) was used for statistical analysis. A p-value of $<0.05$ was considered statistically significant.

\section{RESULTS}

In all, 574 consecutive patients were admitted to the CCU of St John's Medical College from 1 January to 31 December 2008. Data on both gender and age were missing for two patients. Of the 572 patients, 373 (65.2\%) were male. Among the male patients, $166(44.5 \%)$ were aged $\geq 60$ years. Among the 199 female patients, data on age was missing for 3 patients and 3 patients were aged $<18$ years. Of the 193 female patients with available and relevant data on age, 108 (56.0\%) were aged $\geq 60$ years. Among the patients with relevant and complete gender and age data (i.e. 566 patients), 292 (51.6\%) patients were aged 18-59 years and 274 (48.4\%) were aged $\geq 60$ years. A total of 3,832 cardiovascular drugs (mean \pm $\mathrm{SD}=6.7 \pm 2.3$ ) and 1,746 non-cardiovascular drugs (mean \pm $\mathrm{SD}=3.0 \pm 1.9)$ were prescribed to the 574 patients admitted to the CCU. A total of $142(24.7 \%)$ ADRs were reported, of which $32.4 \%$ were cardiovascular and $29.6 \%$ involved electrolyte imbalances.

Of all the patients admitted to the CCU during the study period, the incidence of hypertension, DM, renal dysfunction, acute heart failure, chronic obstructive pulmonary disease (COPD) and unstable angina were higher in patients aged $\geq 60$ years and in male patients aged $\geq 60$ years. Patients aged $\geq 60$ years and female patients aged $\geq 60$ years had significantly higher rates of non-ST elevation myocardial infarction (NSTEMI). The distribution of the study cohort's comorbidities, based on age and gender, is presented in Table I.

We did not find any gender difference in the number of cardiovascular and non-cardiovascular drugs prescribed. However, male patients aged $\geq 60$ years were prescribed significantly more cardiovascular drugs than male patients aged $18-59$ years $(p=0.012)$, and female patients aged $\geq 60$ years were prescribed significantly more non-cardiovascular drugs than those aged $18-59$ years $(p=0.040)$. Prescription of cardiovascular $(p=0.006)$ and non-cardiovascular $(p=0.015)$ drugs were significantly higher in patients aged $\geq 60$ years than in patients aged $18-59$ years (Table II).

Table III shows the utilisation of cardiovascular drugs in the CCU. A significantly higher number of male patients 
Table I. Distribution of comorbidities among patients admitted to the coronary care unit, according to gender and age.

\begin{tabular}{|c|c|c|c|c|c|c|c|c|}
\hline \multirow[t]{2}{*}{ Comorbidity } & \multicolumn{2}{|c|}{ Gender* } & \multicolumn{2}{|c|}{ Age $^{*}$} & \multicolumn{2}{|c|}{ Male } & \multicolumn{2}{|c|}{ Female* } \\
\hline & $\begin{array}{c}\text { Male } \\
373(65.2)\end{array}$ & $\begin{array}{c}\text { Female } \\
199(34.8)\end{array}$ & $\begin{array}{l}18-59 \text { yrs } \\
292(51.6)\end{array}$ & $\begin{array}{c}\geq 60 \text { yrs } \\
274(48.4)\end{array}$ & $\begin{array}{l}18-59 \text { yrs } \\
207(55.5)\end{array}$ & $\begin{array}{c}\geq 60 \text { yrs } \\
166(44.5)\end{array}$ & $\begin{array}{c}18-59 \text { yrs } \\
85(44.0)\end{array}$ & $\begin{array}{c}\geq 60 \mathrm{yrs} \\
108(56.0)\end{array}$ \\
\hline \multicolumn{9}{|l|}{ Significant ${ }^{+}$variables } \\
\hline Hypertension & 201 (53.9) & $125(62.8)^{*}$ & $144(49.3)$ & $176(64.2)^{\ddagger}$ & $96(46.4)$ & $105(63.3)^{*}$ & $48(56.5)$ & $71(65.7)$ \\
\hline Diabetes mellitus & $152(40.8)$ & $96(48.2)$ & $114(39.0)$ & $131(47.8)^{\neq}$ & $72(34.8)$ & $80(48.2)^{*}$ & $42(49.4)$ & $51(47.2)$ \\
\hline Renal dysfunction & 74 (19.8) & $27(13.6)$ & $29(9.9)$ & $71(25.9)^{*}$ & $23(11.1)$ & $51(30.7)^{*}$ & $6(7.1)$ & $20(18.5)^{\ddagger}$ \\
\hline Acute heart failure & $73(19.6)$ & $48(24.1)$ & $40(13.7)$ & $79(28.8)^{*}$ & $28(13.5)$ & $45(27.1)^{\ddagger}$ & $12(14.1)$ & $34(31.5)^{*}$ \\
\hline NSTEMI & $67(18.0)$ & $34(17.1)$ & $39(13.4)$ & $59(21.5)^{\ddagger}$ & $32(15.5)$ & $35(21.1)$ & $7(8.2)$ & $24(22.2)^{*}$ \\
\hline COPD & $39(10.5)$ & $16(8.0)$ & $18(6.2)$ & $37(13.5)^{*}$ & $12(5.8)$ & $27(16.3)^{*}$ & $6(7.1)$ & $10(9.3)$ \\
\hline LRTI & $38(10.2)$ & $22(11.1)$ & $23(7.9)$ & $36(13.1)$ & $14(6.8)$ & $24(14.5)^{*}$ & $9(10.6)$ & $12(11.1)$ \\
\hline Cardiomyopathy & $24(6.4)$ & $10(5.0)$ & $23(7.9)$ & $11(4.0)$ & $15(7.2)$ & $19(11.4)$ & $8(9.4)$ & $2(1.9)^{*}$ \\
\hline Unstable angina & $23(6.2)$ & $17(8.5)$ & $14(4.8)$ & $26(9.5)$ & $8(3.9)$ & $15(9.0)^{*}$ & $6(7.1)$ & $11(10.2)$ \\
\hline Hypothyroidism & $17(4.6)$ & $37(18.6)^{*}$ & $17(5.8)$ & $35(12.8)^{\ddagger}$ & $5(2.4)$ & $12(7.2)$ & $12(14.1)$ & $23(21.3)$ \\
\hline \multicolumn{9}{|c|}{ Nonsignificant variables } \\
\hline STEMI & $108(29.0)$ & $52(26.1)$ & $84(28.8)$ & $73(26.6)$ & $62(30.0)$ & $46(27.7)$ & $22(25.9)$ & $27(25.0)$ \\
\hline Dyslipidaemia & $91(24.4)$ & $45(22.6)$ & $77(26.4)$ & $56(20.4)$ & $54(26.1)$ & 37 (22.3) & $23(27.1)$ & $19(17.6)$ \\
\hline IHD/Stable angina & 65 (17.4) & $36(18.1)$ & $46(15.8)$ & $55(20.1)$ & $30(14.5)$ & $35(21.1)$ & $16(18.8)$ & $20(18.5)$ \\
\hline Arrhythmias & $40(10.7)$ & $21(10.6)$ & $27(9.2)$ & $34(12.4)$ & $20(9.7)$ & $20(12.0)$ & $7(8.2)$ & $14(13.0)$ \\
\hline CVA/Old CVA & $21(5.6)$ & $8(4.0)$ & $15(5.1)$ & $14(5.1)$ & $11(5.3)$ & $10(6.0)$ & $4(4.7)$ & $4(3.7)$ \\
\hline Valvular disease & $11(2.9)$ & $9(4.5)$ & $10(3.4)$ & $10(3.6)$ & $5(2.4)$ & $6(3.6)$ & $5(5.9)$ & $4(3.7)$ \\
\hline PTE & $8(2.1)$ & $7(3.5)$ & $9(3.1)$ & $6(2.2)$ & $4(1.9)$ & $4(2.4)$ & $5(5.9)$ & $2(1.9)$ \\
\hline
\end{tabular}

Note: Data is presented as no. (\%). * Data on gender and age was missing for 2 patients. Data on age was not available for 3 female patients and 3 female patients were aged $<18$ years. ${ }^{\dagger}$ Significant in any one parameter assessed. ${ }^{*}$ Statistically significant $(p<0.05)$.

COPD: chronic obstructive pulmonary disease; CVA: cerebrovascular accident; IHD: ischaemic heart disease; LRTI: lower respiratory tract infection; NSTEMI: non-ST elevation myocardial infraction; PTE: pulmonary thromboembolism; STEMI: ST elevation myocardial infraction

Table II. Differences in the prescription of cardiovascular and non-cardiovascular drugs, according to gender and age.

\begin{tabular}{|c|c|c|c|c|c|c|}
\hline \multirow[t]{2}{*}{ Parameter } & \multicolumn{2}{|c|}{ Cardiovascular drugs } & \multirow[t]{2}{*}{ p-value* } & \multicolumn{2}{|c|}{ Non-cardiovascular drugs } & \multirow[t]{2}{*}{ p-value* } \\
\hline & Mean \pm SD & Median (IQR) & & Mean \pm SD & Median (IQR) & \\
\hline Gender & & & 0.772 & & & 0.119 \\
\hline Female & $6.6 \pm 2.4$ & $7(5,8)$ & & $3.1 \pm 1.8$ & $3(2,4)$ & \\
\hline Age (yrs) & & & $0.006^{+}$ & & & $0.015^{+}$ \\
\hline $18-59$ & $6.4 \pm 2.5$ & $6(5,8)$ & & $2.9 \pm 1.9$ & $3(2,4)$ & \\
\hline \multicolumn{7}{|l|}{ Gender by age } \\
\hline Male (yrs) & & & $0.012^{+}$ & & & 0.105 \\
\hline $18-59$ & $6.4 \pm 2.4$ & $6(5,8)$ & & $2.8 \pm 1.9$ & $2(1,4)$ & \\
\hline$\geq 60$ & $7.1 \pm 2.1$ & $7(6,8)$ & & $3.3 \pm 2.0$ & $3(2,4)$ & \\
\hline Female (yrs) & & & 0.154 & & & $0.040^{+}$ \\
\hline $18-59$ & $6.3 \pm 2.7$ & $6(4.5,8)$ & & $2.9 \pm 1.4$ & $3(2,4)$ & \\
\hline$\geq 60$ & $6.8 \pm 2.1$ & $7(5,8)$ & & $3.4 \pm 1.5$ & $3(2,4)$ & \\
\hline
\end{tabular}

${ }^{*}$ Mann-Whitney $U$ test was used for analysis. ${ }^{+}$Statistically significant $(p<0.05)$. IQR: interquartile range; SD: standard deviation

were prescribed antiplatelets as compared to female patients $(p=0.023)$. When compared with male patients aged 18-59 years, the prescriptions of antiplatelets $(p=0.014)$, lipidlowering drugs $(p=0.01)$, and diuretics $(p=0.001)$ were significantly higher among male patients aged $\geq 60$ years. Similar results were found when female patients aged 18-59 years were compared with those aged $\geq 60$ years; the prescriptions of antiplatelets $(p=0.007)$, lipid-lowering drugs $(p=0.003)$, and diuretics $(p=0.003)$ were significantly higher in the latter. Utilisation of calcium channel blockers (CCBs) was significantly higher in male patients aged $\geq 60$ years than in those aged 18 59 years $(p=0.005)$. Female patients aged $\geq 60$ years were prescribed significantly more antiarrhythmics than those aged $18-59$ years $(p=0.008)$. When compared with patients aged $18-59$ years, patients aged $\geq 60$ years were prescribed significantly more antiplatelets $(p=0.001)$, diuretics $(p=$ 0.0001), and antiarrhythmics $(p=0.034)$. Lipid-lowering drugs
( $p=0.0001)$ and beta blockers $(p=0.015)$ were used more frequently in patients aged $18-59$ years than in patients aged $\geq 60$ years.

Overall, the proportion of patients receiving polypharmacy was significantly higher in patients aged $\geq 60$ years than in those aged $18-59$ years $(p=0.001)$. Male patients aged $\geq 60$ years also had higher rates of polypharmacy than male patients aged 18-59 years $(p=0.001)$ (Table IV).

We did not observe any significant gender differences with regard to the occurrence of ADRs $(p=0.262)$. The frequency of ADRs was significantly higher in patients aged $\geq 60$ years than in those aged $18-59$ years $(p=0.013)$. ADRs related to electrolyte imbalances were more common in female patients than male patients $(p=0.001)$. Compared to patients aged $18-59$ years, those aged $\geq 60$ years had significantly more ADRs related to the renal system $(p=0.047)$ and skin $(p=0.003)($ Table V). 
Table III. Utilisation patterns of cardiovascular drugs in the coronary care unit, according to gender and age.

\begin{tabular}{|c|c|c|c|c|c|c|c|c|}
\hline \multirow[t]{2}{*}{ Drug prescribed } & \multicolumn{2}{|c|}{ Gender* } & \multicolumn{2}{|c|}{ Age* } & \multicolumn{2}{|c|}{ Male } & \multicolumn{2}{|c|}{ Female* } \\
\hline & $\begin{array}{c}\text { Male } \\
373(65.2)\end{array}$ & $\begin{array}{c}\text { Female } \\
199(34.8)\end{array}$ & $\begin{array}{l}18-59 \text { yrs } \\
292(51.6)\end{array}$ & $\begin{array}{c}\geq 60 \text { yrs } \\
274(48.4)\end{array}$ & $\begin{array}{l}18-59 \text { yrs } \\
207(55.5)\end{array}$ & $\begin{array}{c}\geq 60 \text { yrs } \\
166(44.5)\end{array}$ & $\begin{array}{l}18-59 \text { yrs } \\
85(44.0)\end{array}$ & $\begin{array}{c}\geq 60 \mathrm{yrs} \\
108(56.0)\end{array}$ \\
\hline \multicolumn{9}{|l|}{ Significant $^{+}$variables } \\
\hline Antiplatelets & 340 (91.2) & $169(84.9)^{\ddagger}$ & 247 (84.6) & $256(93.4)^{*}$ & $182(87.9)$ & $158(95.2)^{\ddagger}$ & 65 (76.5) & $98(90.7)^{*}$ \\
\hline Lipid-lowering & $294(78.8)$ & $144(72.4)$ & 228 (78.1) & $205(74.8)^{*}$ & $153(73.9)$ & $141(84.9)^{\ddagger}$ & $52(61.2)$ & $87(80.6)^{\ddagger}$ \\
\hline Beta blockers & 218 (58.4) & 115 (57.8) & $183(62.7)$ & $144(52.6)^{*}$ & $131(63.3)$ & 87 (52.4) & $52(61.2)$ & $57(52.8)$ \\
\hline Diuretics & 163 (43.7) & $100(50.3)$ & 96 (32.9) & $163(59.5)^{*}$ & $64(30.9)$ & $99(59.6)^{\ddagger}$ & $32(37.6)$ & $64(59.3)^{\neq}$ \\
\hline $\mathrm{CCBs}$ & $95(25.5)$ & $66(33.2)$ & 72 (24.7) & 87 (31.8) & 41 (19.8) & $54(32.5)^{*}$ & $31(36.5)$ & 33 (30.6) \\
\hline Antiarrhythmics & $37(9.9)$ & $16(8.0)$ & $20(6.8)$ & $33(12.0)^{\neq}$ & $18(8.7)$ & $19(11.4)$ & $2(2.4)$ & $14(13.0)^{\neq}$ \\
\hline \multicolumn{9}{|l|}{ Nonsignificant variables } \\
\hline ACE-i/ARBs & $266(71.3)$ & $140(70.4)$ & $203(69.5)$ & $197(71.9)$ & $144(69.6)$ & $122(73.5)$ & $59(69.4)$ & $79(73.1)$ \\
\hline $\begin{array}{l}\text { Heparin, vitamin } \mathrm{K} \\
\text { antagonist, } \\
\text { antithrombotics }\end{array}$ & $238(63.8)$ & $136(68.3)$ & $191(65.4)$ & $177(64.6)$ & $135(65.2)$ & $103(62.0)$ & $56(65.9)$ & $74(68.5)$ \\
\hline Vasodilators & $164(44.0)$ & $94(47.2)$ & $122(41.8)$ & $133(48.5)$ & $82(39.6)$ & $82(49.4)$ & $40(47.1)$ & $51(47.2)$ \\
\hline $\begin{array}{l}\text { Other cardiac } \\
\text { preparations }\end{array}$ & $58(15.5)$ & $28(14.1)$ & $43(14.7)$ & $39(14.2)$ & $29(14.0)$ & $29(17.5)$ & $10(11.8)$ & $14(13.0)$ \\
\hline Cardiac glycosides & $44(11.8)$ & $16(8.0)$ & $29(9.9)$ & 31 (11.3) & $19(9.2)$ & $25(15.1)$ & $10(11.8)$ & $6(5.6)$ \\
\hline Enzymes (fibrinolytics) & $32(8.6)$ & $15(7.5)$ & $25(8.6)$ & $20(7.3)$ & $19(9.2)$ & $13(7.8)$ & $6(7.1)$ & $7(6.5)$ \\
\hline Cardiac stimulants & $19(5.1)$ & $13(6.5)$ & $17(5.8)$ & $15(5.5)$ & $14(6.8)$ & $5(3.0)$ & $3(3.5)$ & $10(9.3)$ \\
\hline $\begin{array}{l}\alpha \text {-blockers and } \\
\text { centrally-acting } \\
\text { antihypertensives }\end{array}$ & $16(4.3)$ & $8(4.0)$ & $12(4.1)$ & $12(4.4)$ & $7(3.4)$ & $9(5.4)$ & $5(5.9)$ & $3(2.8)$ \\
\hline
\end{tabular}

Note: Data is presented as no. (\%). *Data on gender and age was missing for 2 patients. Data on age was not available for 3 female patients and 3 female patients were aged $<18$ years. ${ }^{\dagger}$ Significant in any one parameter assessed. ${ }^{\ddagger}$ Statistically significant $(p<0.05)$.

ACE-i: angiotensin-converting enzyme inhibitors; ARBs: angiotensin receptor blockers; CCBs: calcium channel blockers

Table IV. Differences in polypharmacy, according to gender and age.

\begin{tabular}{|c|c|c|c|c|}
\hline Parameter & All & $<10$ drugs & $\geq 10$ drugs & p-value ${ }^{+}$ \\
\hline $\begin{array}{l}\text { Gender* } \\
\text { Male } \\
\text { Female }\end{array}$ & $\begin{array}{l}373(65.2) \\
199(34.8)\end{array}$ & $\begin{array}{r}180(48.3) \\
92(46.2)\end{array}$ & $\begin{array}{l}193(51.7) \\
107(53.8)\end{array}$ & 0.064 \\
\hline $\begin{array}{l}\text { Age* (yrs) }^{*} \\
18-59 \\
\geq 60\end{array}$ & $\begin{array}{l}292(51.6) \\
274(48.4)\end{array}$ & $\begin{array}{l}159(54.5) \\
113(41.2)\end{array}$ & $\begin{array}{l}133(45.5) \\
161(58.8)\end{array}$ & $0.001^{*}$ \\
\hline $\begin{array}{l}\text { Gender by age } \\
\text { Male (yrs) } \\
18-59 \\
\geq 60\end{array}$ & $\begin{array}{l}207(55.5) \\
166(44.5)\end{array}$ & $\begin{array}{r}116(56.0) \\
64(38.6)\end{array}$ & $\begin{array}{r}91(44.0) \\
102(61.4)\end{array}$ & $0.001^{*}$ \\
\hline $\begin{array}{l}\text { Female* (yrs) } \\
18-59 \\
\geq 60\end{array}$ & $\begin{array}{r}85(44.0) \\
108(56.0)\end{array}$ & $\begin{array}{l}43(50.6) \\
49(45.4)\end{array}$ & $\begin{array}{l}42(49.4) \\
59(54.6)\end{array}$ & 0.471 \\
\hline
\end{tabular}

Note: Data is presented as no. (\%). * Data on gender and age was missing for 2 patients. Data on age was not available for 3 female patients and 3 female patients were aged $<18$ years. ${ }^{\dagger}$ Mann-Whitney $U$ test was used for analysis. ${ }^{*}$ Statistically significant $(p<0.05)$.

Although the median duration of CCU stay was the same in both male and female patients, the median duration of hospital stay was significantly longer in the male patients when compared to the female patients $(p=0.008)$. CCU stay was found to be longer in patients aged $\geq 60$ years $(p=0.013)$ and in male patients aged $\geq 60$ years $(p=0.013)$ (Table VI).

\section{DISCUSSION}

In the present study we found that the incidence of hypertension was significantly higher in female patients than in male patients $(p=0.040)$ (Table I). Previous studies have also reported an increased likelihood of women having a history of hypertension. ${ }^{(21,22)}$ Systolic blood pressure rises more steeply in ageing women than in ageing men.

We also observed a significant difference in the occurrence of NSTEMI in female patients aged $\geq 60$ years when compared to its occurrence in female patients aged 18-59 years ( $p=0.009$ ). It has been hypothesised that the progression of atheroma into more vulnerable plaques develops at a slower rate in middle-aged women, with a more diffuse pattern of atherosclerosis occurring after menopause and outward remodelling. ${ }^{(23)}$ Women have more inflammation in the coronary arteries than men, and classical patterns of plaque rupture and subsequent thrombus formation is more common in older women than in younger women. ${ }^{(24)}$

Patients aged $\geq 60$ years had more prescriptions of cardiovascular $(p=0.006)$ and non-cardiovascular drugs ( $p=0.015)$. Cardiovascular drug prescription was significantly higher in male patients aged $\geq 60$ years than in male patients aged $18-59$ years, while female patients aged $\geq 60$ years were prescribed more non-cardiovascular drugs than those aged 18-59 years. This could be due to the greater number of 
Table V. Adverse drug reactions that occurred in patients admitted to the coronary care unit, according to gender and age.

\begin{tabular}{|c|c|c|c|c|}
\hline \multirow[t]{2}{*}{ Adverse drug reaction } & \multicolumn{2}{|c|}{ Gender } & \multicolumn{2}{|c|}{ Age } \\
\hline & Male $(n=373)$ & Female $(n=199)$ & $18-59$ yrs $(n=292)$ & $\geq 60$ yrs $(n=274)$ \\
\hline Overall & $87(23.3)$ & $55(27.6)$ & $57(19.5)$ & $82(29.9)^{+}$ \\
\hline \multicolumn{5}{|l|}{ Significant* variables } \\
\hline Renal complications & $17(4.6)$ & $8(4.0)$ & $10(3.4)$ & $15(5.5)^{\dagger}$ \\
\hline Electrolyte imbalance & $16(4.3)$ & $26(13.1)^{+}$ & $14(4.8)$ & $27(9.9)$ \\
\hline Cutaneous complications & $4(1.1)$ & $2(1.0)$ & $1(0.3)$ & $4(1.5)^{\dagger}$ \\
\hline \multicolumn{5}{|l|}{ Nonsignificant variables } \\
\hline Cardiovascular complications & $33(8.8)$ & $13(6.5)$ & $21(7.2)$ & $24(8.8)$ \\
\hline Haematological complications & $17(4.6)$ & $5(2.5)$ & $13(4.5)$ & $9(3.3)$ \\
\hline Metabolic complications & $8(2.1)$ & $2(1.0)$ & $4(1.4)$ & $6(2.2)$ \\
\hline GI system complications & $7(1.9)$ & $6(3.0)$ & $3(1.0)$ & $10(3.6)$ \\
\hline CNS complications & $5(1.3)$ & $1(0.5)$ & $2(0.7)$ & $4(1.5)$ \\
\hline Liver complications & $2(0.5)$ & $0(0)$ & $1(0.3)$ & $1(0.4)$ \\
\hline Respiratory complications & $1(0.3)$ & $1(0.5)$ & $1(0.3)$ & $1(0.4)$ \\
\hline Skeletal complications & $0(0)$ & $1(0.5)$ & $1(0.3)$ & $0(0)$ \\
\hline
\end{tabular}

Data is presented as no. (\%). * Significant in any one parameter assessed. ${ }^{\dagger}$ Statistically significant ( $\left.<<0.05\right)$. CNS: central nervous system; GI: gastrointestinal

Table VI. Duration of hospital stay and the coronary care unit (CCU), according to gender and age.

\begin{tabular}{|c|c|c|c|c|c|c|}
\hline \multirow[t]{2}{*}{ Parameter } & \multicolumn{2}{|c|}{ Hospital stay (days) } & \multirow[t]{2}{*}{ p-value* } & \multicolumn{2}{|c|}{ CCU stay (days) } & \multirow[t]{2}{*}{ p-value* } \\
\hline & Mean \pm SD & Median (IQR) & & Mean \pm SD & Median (IQR) & \\
\hline Gender & & & $0.008^{+}$ & & & 0.523 \\
\hline Female & $7.3 \pm 6.5$ & $6(4,9)$ & & $2.9 \pm 2.1$ & $3(2,3)$ & \\
\hline Age (yrs) & & & 0.109 & & & $0.013^{+}$ \\
\hline $18-59$ & $8.3 \pm 7.6$ & $6(4,10)$ & & $3.1 \pm 4.6$ & $2.5(2,3)$ & \\
\hline \multicolumn{7}{|l|}{ Gender by age } \\
\hline Male (yrs) & & & 0.800 & & & $0.013^{+}$ \\
\hline $18-59$ & $8.9 \pm 8.5$ & $6(4,10)$ & & $3.2 \pm 5.3$ & $2(2,3)$ & \\
\hline$\geq 60$ & $8.8 \pm 5.4$ & $7.5(5,12)$ & & $3.2 \pm 1.9$ & $3(2,4)$ & \\
\hline Female (yrs) & & & 0.436 & & & 0.338 \\
\hline $18-59$ & $6.7 \pm 4.0$ & $6(4,9)$ & & $2.8 \pm 1.9$ & $3(2,3)$ & \\
\hline$\geq 60$ & $7.9 \pm 8.1$ & $6(4,9)$ & & $3.1 \pm 2.3$ & $3(2,3)$ & \\
\hline
\end{tabular}

${ }^{*}$ Mann-Whitney $U$ test was used for analysis. ${ }^{+}$Statistically significant $(p<0.05)$. IQR: interquartile range; SD: standard deviation

comorbidities and associated infections, such as lower respiratory tract infections, urinary tract infections and COPD, in the elderly population.

In the present study, higher rates of utilisation of antiplatelets, lipid-lowering drugs and diuretics were observed in male and female patients aged $\geq 60$ years. Banerjee et $\mathrm{al}^{(25)}$ and Sharma and Ganguly ${ }^{(26)}$ reported similar results in male patients and patients aged $>65$ years. The higher rates of utilisation of diuretics in our study could be attributed to the higher occurrences of heart failure and renal dysfunction in the patients aged $\geq 60$ years (both male and female). This correlates well with standard management guidelines. ${ }^{(27-29)}$ A higher percentage of patients aged 18-59 years were taking lipid-lowering drugs compared to patients aged $\geq 60$ years (78.1.\% vs $74.8 \%$ ). Ko et al showed that in addition to statin prescription rates being low in their study cohort, the likelihood of statin treatment was $6.4 \%$ lower with every one-year increase in age. ${ }^{(10)}$

Similar to the trend observed in the utilisation of lipidlowering drugs, we observed that the utilisation of beta blockers in patients aged $18-59$ years $(62.7 \%)$ was higher than that in patients aged $\geq 60$ years. The CREATE registry reported a similar percentage of beta blocker use in STEMI (57.5\%) and non-STEMI/unstable angina $(61.9 \%)$ patients with the mean ages of 56.3 years and 59.3 years, respectively. ${ }^{(30)}$ The less frequent use of beta blockers in patients aged $\geq 60$ years (52.6\%) could be due to the higher incidence of heart failure, DM, COPD and heart block in this age group. While the benefits of beta blocker use on mortality has been well established in several large trials conducted among patients with mild-to-moderate heart failure, ${ }^{(31,32)}$ guidelines recommend initiation of beta blocker therapy once a patient's clinical condition has remained stable for at least $24-48$ hours. ${ }^{(33)}$

The use of angiotensin-converting enzyme inhibitors/ angiotensin receptor blockers (ACE-i/ARBs) in female patients was not significantly different from their use in male patients $(70.4 \%$ vs $71.3 \% ; p=0.809)$. Driscoll et al ${ }^{(11)}$ reported that women are less likely to be prescribed antihypertensives as compared to men (58\% vs 62\%; $\mathrm{p}<0.001)$. While an Estonian study in 2010 reported that only $40 \%$ of their patients were treated with ACE-i/ARBs, ${ }^{(34)}$ the use of ACE-i/ARBs in our study cohort was $70 \%$. However, compared to the study by 
Ghosh et $\mathrm{al}^{(35)}$ that reported the use of ACE-i/ARBs in $87 \%$ of their patients, it appears that there is an underutilisation of ACE-i/ARBs in CVDs. The underutilisation of drugs is a multifactorial problem that could be due to misperceptions and concerns regarding drug safety and adverse effects. Other reasons may be related to polypharmacy, the patient's compliance with treatment, and the physician's compliance with evidence-based practice.

The use of antiarrhythmics was significantly higher in female patients aged $\geq 60$ years $(13.0 \%)$ and in patients aged $\geq 60$ years $(12.0 \%)$. This might be due to the high rate of arrhythmias observed in female patients aged $\geq 60$ years $(13.0 \%)$ and in patients aged $\geq 60$ years $(12.4 \%)$. Compared to normal myocytes, failing myocytes have longer action potentials and a greater susceptibility to early after-depolarisations. Longer action potentials and a greater susceptibility to early afterdepolarisations are more commonly seen in the myocytes of female patients due to the slightly larger depolarising of L-type calcium channels and slightly smaller repolarising of potassium channels. ${ }^{(36)}$

A significantly higher use of CCBs was observed in male patients aged $\geq 60$ years. This observation is in line with the 2011 NICE guidelines, which recommend the use of CCBs in patients aged $\geq 55$ years. ${ }^{(37)}$ Blood pressure is more effectively lowered with the use of calcium antagonists in older than younger patients with hypertension. CCBs, which are preferred in elderly patients, prevent calcium from entering the muscle cells of the heart and blood vessels, relaxing the blood vessels and decreasing the blood pressure.

When examining polypharmacy in our study cohort, we found that patients aged $\geq 60$ years had a significantly higher rate of polypharmacy than patients aged 18-59 years. However, when further stratified according to age in gender, the difference was only significant for male patients. For female patients, the prevalence of polypharmacy was not significantly different between the two age groups. This may be because there is a greater use of medications in younger women, as well as a lower use of medications in older women. The greater use of medications in younger women could be because, compared to men, younger women tend to be more concerned about their health. They also tend to recognise and experience health problems early, and therefore consult physicians more often and earlier than men. Younger women are also more accustomed to the use of drugs. ${ }^{(38,39)}$ The lower use of medications in older women, however, could be due to the differences in the pharmacokinetic parameters of older women, which increases their risk of ADRs. ${ }^{(13)}$

In our study, patients aged $\geq 60$ years had a higher rate of ADRs (29.9\%), and the ADRs were predominantly associated with the renal system and skin. Patients aged $\geq 60$ years are more prone to renal dysfunction, decreased renal clearance and decreased drug metabolism capacity. Renal dysfunction enhances the risk of developing Type A pharmacologically predictable reactions for renally excreted drugs. ${ }^{(40)}$ As the proportion of patients with renal dysfunction in the $\mathrm{CCU}$ is relatively high, the proportion of ADRs, such as hyperkalaemia, azotaemia and acute renal failure, induced by ACE-i was also high. In many instances, these ADRs were potentially preventable with the use of better dose titrations and diuretic level adjustments. As these are general risk factors that have been shown to increase the risk of ADRs, special care has to be exercised when prescribing medications to patients aged $\geq 60$ years. We did not observe any significant difference in the ADR rates of the male and female patients.

Electrolyte imbalance was more commonly reported in female patients $(13.1 \%)$ in our study. However, previous studies have reported female patients to have a high risk of hypersensitivity reactions and ADRs that are related to the gastrointestinal system. ${ }^{(41)}$ In our study, the number of ADRs involving the cardiovascular system were almost equal in the two age groups, and more commonly observed in male patients. Mohebbi et al reported that patients in their ADR group were significantly older and that the cardiovascular system was the main organ system involved in the ADRs. ${ }^{(16)}$ One study reported that ADRs related to the central and peripheral nervous systems were more common in CCUs. ${ }^{(42)}$ Cardiovascular drugs could result in fatal adverse reactions in $\mathrm{CCU}$ patients. The primary diagnosis at admission and the duration of CCU stay were reported to be risk factors for ADR development. ${ }^{(42)}$

In the present study, the duration of hospital stay was significantly longer for the male patients than for the female patients. CCU stay was significantly longer for patients aged $\geq 60$ years and male patients aged $\geq 60$ years. This can be attributed to the greater number of comorbidities, the higher incidence of polypharmacy and the higher rates of ADRs in male patients and patients aged $\geq 60$ years. It has been hypothesised that the risk of having an ADR increases exponentially as the number of medicines taken by the patient increases. $^{(43)}$

This study has its strengths and limitations. One of the strengths of the present study is that it is one of the few studies conducted to examine age and gender differences in CVDs, including the use of drugs and the characteristics of ADRs in a CCU. The findings of the present study clearly highlight the need for patient age to be taken into consideration when initiating pharmacotherapy for CVDs, especially in critical care settings. Unlike other studies, ${ }^{(7-11,13)}$ the present study did not find any major differences in the use of drugs and the patterns of ADRs between male and female patients. This suggests that ADRs in female patients are potentially preventable if pharmacotherapy is optimised according to gender.

The present study was a retrospective cohort study based on the review of hospital medical records. Retrospective collection of data in ADR studies may lead to lower ADR rates. However, although prospective studies in theory generate more accurate data due to the greater intensity of data 
collection, retrospective studies are acceptable for examining drug utilisation and ADRs. Large prospective studies with larger sample sizes are recommended to accurately estimate the age- and gender-related differences in the rate of CVDs, drug utilisation pattern, and characteristics of ADRs in a critical care setting.

In conclusion, no major gender-related differences were observed in drug utilisation or ADR pattern in the present study. Higher rates of drug utilisation and ADRs, and longer duration of $\mathrm{CCU}$ stay were observed in patients aged $\geq 60$ years. With continued improvements in healthcare, people are living longer, thus leading to an increased elderly population size. Frequent reviews of drug utilisation, and newer strategies for active and vigilant monitoring of ADRs, are essential to prevent ADRs and optimise pharmacotherapy, especially in elderly patients in intensive care settings.

\section{ACKNOWLEDGEMENTS}

The authors sincerely and gratefully acknowledge Mrs Sushma Santosh, Senior Research Fellow, Pharmacovigillance Centre, Department of Pharmacology, St John's Medical College, Bangalore, for her contribution to the data collection. We also thank Mrs Sumitra, Biostatistician, St John's Research Institute, Bangalore, for her indispensable contribution to the statistical analysis.

\section{REFERENCES}

1. Surveillance of mortality and cardiovascular disease related morbidity in Industrial settings. WHO Country Office for India, Geneva, Switzerland [online]. Available at: www.georgeinstitute.org.au/global-health-landscape/ global-health-resources-chronic-diseases/key-statistics-chronic-diseases. Accessed July 3, 2011.

2. Rosamond W, Flegal K, Furie K, et al. Heart disease and stroke statistics--2008 update: a report from the American Heart Association Statistics Committee and Stroke Statistics Subcommittee. Circulation 2008; 117:e25-146.

3. Mendelson MA, Hendel RC. Myocardial infarction in women. Cardiology 1995; 86:272-85.

4. Jousilahti P, Vartiainen E, Tuomilehto J, Puska P. Sex, age, cardiovascular risk factors, and coronary heart disease: a prospective follow-up study of 14786 middle-aged men and women in Finland. Circulation 1999; 99:1165-72.

5. Anand SS, Islam S, Rosengren A, et al. Risk factors for myocardial infarction in women and men: insights from the INTERHEART study. Eur Heart J 2008; 29:932-40.

6. Towfighi A, Zheng L, Ovbiagele B. Sex-specific trends in midlife coronary heart disease risk and prevalence. Arch Intern Med 2009; 169:1762-6.

7. Vulic D, Lee BT, Dede J, Lopez VA, Wong ND. Extent of control of cardiovascular risk factors and adherence to recommended therapies in US multiethnic adults with coronary heart disease: from a 2005-2006 national survey. Am J Cardiovasc Drugs 2010; 10:109-14.

8. de Ruijter W, de Waal MW, Gussekloo J, Assendelft WJ, Blom JW. Time trends in preventive drug treatment after myocardial infarction in older patients. Br J Gen Pract 2010; 60:47-9.

9. Gnavi R, Migliardi A, Demaria M, et al. Statins prescribing for the secondary prevention of ischaemic heart disease in Torino, Italy. A case of ageism and social inequalities. Eur J Public Health 2007; 17:492-6.

10. Ko DT, Mamdani M, Alter DA. Lipid-lowering therapy with statins in highrisk elderly patients: the treatment-risk paradox. JAMA 2004; 291:1864-70.

11. Driscoll A, Beauchamp A, Lyubomirsky G, et al. Suboptimal management of cardiovascular risk factors in coronary heart disease patients in primary care occurs particularly in women. Intern Med J 2011; 41:730-6.
12. Bates DW, Spell N, Cullen DJ, et al. The costs of adverse drug events in hospitalized patients. Adverse Drug Events Prevention Study Group. JAMA 1997; 277:307-11.

13. Rademaker M. Do women have more adverse drug reactions? Am J Clin Dermatol 2001; 2:349-51.

14. Gurwitz JH, Avorn J. The ambiguous relation between aging and adverse drug reactions. Ann Intern Med 1991; 114:956-66.

15. Davies EC, Green CF, Mottram DR, Pirmohamed M. Adverse drug reactions in hospitals: a narrative review. Curr Drug Saf 2007; 2:79-87.

16. Mohebbi N, Shalviri G, Salarifar M, Salamzadeh J, Gholami K. Adverse drug reactions induced by cardiovascular drugs in cardiovascular care unit patients. Pharmacoepidemiol Drug Saf 2010; 19:889-94.

17. Devi P, Kamath DY, Anthony N, Santosh S, Dias B. Patterns, predictors and preventability of adverse drug reactions in the coronary care unit of a tertiary care hospital. Eur J Clin Pharmacol 2012; 68:427-33.

18. WHO Collaborating Centre for Drug Statistics Methodology. Guidelines for ATC classification and DDD assignment 2011. Oslo, 2010. 1-8-2012 [online]. Available at: www.whocc.no/filearchive/publications/2011guidelines.pdf. Accessed August 1, 2012.

19. World Health Organization. International Classification of Diseases Version 10. 1-8-2012 [online]. Available at: www.apps.who.int/classifications/ icd10/browse/2010/en. Accessed August 1, 2012.

20. World Health Organization. International drug monitoring- the role of national centres. Technical Report No.498, World Health Organisation, Geneva [online]. Available at: www.who-umc.org/graphics/24756.pdf. Accessed August 1, 2012.

21. Blomkalns AL, Chen AY, Hochman JS, et al. Gender disparities in the diagnosis and treatment of non-ST-segment elevation acute coronary syndromes: large-scale observations from the CRUSADE (Can Rapid Risk Stratification of Unstable Angina Patients Suppress Adverse Outcomes With Early Implementation of the American College of Cardiology/ American Heart Association Guidelines) National Quality Improvement Initiative. J Am Coll Cardiol 2005; 45:832-7.

22. Stone PH, Thompson B, Anderson HV, et al. Influence of race, sex, and age on management of unstable angina and non-Q-wave myocardial infarction: The TIMI III registry. JAMA 1996; 275:1104-12.

23. Shaw LJ, Bugiardini R, Merz CN. Women and ischemic heart disease: evolving knowledge. J Am Coll Cardiol 2009; 54:1561-75.

24. Camici PG, Crea F. Coronary microvascular dysfunction. N Engl J Med 2007; 356:830-40.

25. Banerjee S, Kumar V, Ramachandran P, Kamath A. Does The Pharmacological Management Of Unstable Angina Vary With Age And Gender - A Descriptive Study. J Clin Diag Res 2010; 4:3150-57.

26. Sharma M, Ganguly NK. Premature coronary artery disease in Indians and its associated risk factors. Vasc Health Risk Manag 2005; 1:217-25.

27. National Kidney Foundation. K/DOQI clinical practice guidelines for chronic kidney disease: evaluation, classification, and stratification. Am J Kidney Dis 2002; 39 (2 suppl 1):S1-266.

28. National Institute for Health and Clinical Excellence, United Kingdom. Chronic Heart Failure: Management of chronic heart failure in adults in primary and secondary care (Issued: August 2010). Available at: http:// www.nice.org.uk/nicemedia/live/13099/50517/50517.pdf. Accessed March 24, 2014.

29. National Institute for Health and Care Excellence, United Kingdom. Chronic kidney disease: Early identification and management of chronic kidney disease in adults in primary and secondary care (Issued: September 2008). Available at: http://www.nice.org.uk/nicemedia/ live/12069/42117/42117.pdf. Accessed March 24, 2014.

30. Xavier D, Pais P, Devereaux PJ, et al. Treatment and outcomes of acute coronary syndromes in India (CREATE): a prospective analysis of registry data. Lancet 2008; 371:1435-42.

31. Tepper D. Frontiers in congestive heart failure: Effect of Metoprolol CR/XL in chronic heart failure: Metoprolol CR/XL Randomised Intervention Trial in Congestive Heart Failure (MERIT-HF). Congest Heart Fail 1999; 5:184-5.

32. Packer M, Coats AJ, Fowler MB, et al. Effect of carvedilol on survival in severe chronic heart failure. N Engl J Med 2001; 344:1651-8.

33. Hunt SA, Abraham WT, Chin MH, et al. 2009 focused update incorporated into the ACC/AHA 2005 Guidelines for the Diagnosis and Management of Heart Failure in Adults: a report of the American College of Cardiology Foundation/American Heart Association Task Force on Practice Guidelines: developed in collaboration with the International Society for Heart and Lung Transplantation. Circulation 2009; 119:e391-e479. 
34. Marandi T, Baburin A, Ainla T. Use of evidence-based pharmacotherapy after myocardial infarction in Estonia. BMC Public Health 2010; 10:358.

35. Ghosh A, Das AK, Pramanik S, Saha UK. Drug utilization study in patients of acute coronary syndrome on follow-up visits at a tertiary care centre In Kolkata. Asian J Pharm Life Sci 2013; 2:155-65.

36. Verkerk AO, Wilders R, Veldkamp MW, et al. Gender disparities in cardiac cellular electrophysiology and arrhythmia susceptibility in human failing ventricular myocytes. Int Heart J 2005; 46:1105-18.

37. Krause T, Lovibond K, Caulfield M, McCormack T, Williams B. Management of hypertension: summary of NICE guidance. BMJ 2011; 343:d4891.

38. Zaitune MP, Barros MB, Cesar CL, Carandina L, Goldbaum M. [Arterial hypertension in the elderly: prevalence, associated factors, and control practices in Campinas, Sao Paulo, Brazil]. Cad Saude Publica 2006; 22:285-94. Portuguese.
39. Suominen-Taipale AL, Martelin T, Koskinen S, Holmen J, Johnsen R. Gender differences in health care use among the elderly population in areas of Norway and Finland. A cross-sectional analysis based on the HUNT study and the FINRISK Senior Survey. BMC Health Serv Res 2006; 6:110

40. Davies EC, Green CF, Mottram DR, Pirmohamed M. Adverse drug reactions in hospitals: a narrative review. Curr Drug Saf 2007; 2:79-87.

41. Domecq C, Naranjo CA, Ruiz I, Busto U. Sex-related variations in the frequency and characteristics of adverse drug reactions. Int J Clin Pharmacol Ther Toxicol 1980; 18:362-6.

42. Karimzadeh I, Namazi S, Shalviri G, Gholami K. Cardiovascular drug adverse reactions in hospitalized patients in cardiac care unit. African J Pharm Pharmacol 2011; 5:493-9.

43. Routledge PA, O'Mahony MS, Woodhouse KW. Adverse drug reactions in elderly patients. Br J Clin Pharmacol 2004; 57:121-6. 